\title{
REDES SOCIALES Y EMIGRACIÓN: EL CASO DE LOS MARPLATENSES ${ }^{1}$
}

\author{
POR \\ ELDA GONZÁLEZ MARTÍNEZ \\ Instituto de Historia, Centro de Ciencias Sociales y Humanas (CSIC)
}

Este articulo describe la última oleada de inmigración argentina en España, aquella que se produjo a raíz de la crisis que afectó al país a comienzos del nuevo milenio. A partir de entrevistas, documentación de prensa y fuentes estadísticas se analiza el papel de las redes sociales como factor que facilita, en primer lugar, la elección de destino a los emigrantes marplatenses, mientras que más tarde contribuye al proceso de asentamiento en las Baleares.

PALABRAS ClAVE: Emigración, red social, marplatenses, España.

A comienzos de diciembre de 2001 estalla en la Argentina una crisis que afecta muy profundamente a la población del país. Hacia finales de ese mes los presidentes de gobierno se fueron sucediendo, alguno de ellos sólo ejerció como tal un puñado de días, la población reaccionó rechazando a sus dirigentes políticos y al sistema judicial, utilizando una herramienta muy pacífica, los llamados «cacerolazos». «Que se vayan todos», fue el grito que unió a los argentinos.

Unos pocos días antes, el sistema financiero se había visto amenazado por los clientes bancarios que retiraban el dinero que tenían depositado. Como medida de emergencia fue sancionada una ley que dispuso la limitación a la extracción de fondos en todo tipo de cuentas, quedaba así instaurado el popularmente conocido como «corralito» ${ }^{2}$. Asociado a la crisis financiera, el desempleo se agravó de tal manera que, en la primera mitad del año 2002, alcanzó al $21.5 \%$ de la población económicamente activa.

\footnotetext{
1 Este artículo se inserta en el proyecto de investigación HUM2006-00765, financiado por el MEC.

2 Palomino, 2003. Sevares, 2002. Basualdo, 2006.
} 
La falta de trabajo - junto a otros factores tales como la desconfianza que algunos manifiestan sentir por el país, la inseguridad ciudadana, el deterioro de los sistemas sanitarios y educativos, entre otros - ejercieron una fuerte presión sobre la población argentina, en especial los más jóvenes se vieron impulsados a buscar nuevas oportunidades en otros países ${ }^{3}$.

En esa época empezó a circular entre ellos un chiste: «¿Sabés cuál es la única salida posible a la crisis? ¡Ezeiza! ${ }^{4}$. El mensaje que llevaba implícito el chascarrillo era utilizado y repetido por los medios de difusión, con comentarios del tipo: «Hay un corralito a la ilusión. Cuando emigrar se convierte en una cuestión cultural» $»^{5}$, «Argentinos en liquidación» ${ }^{6} \mathrm{o}$ «Argentinos en busca de insólitas nacionalidades para emigrar. Tras los pasos del abuelo turco» ${ }^{7}$.

Como este último titular indicaba, se inició la reconstrucción de árboles genealógicos con la finalidad de encontrar algún documento que permitiera obtener un pasaporte, que diese acceso a la residencia en Europa. Interminables filas ante los consulados de diversos países empezaron a ser habituales en la época, e incluso se extendieron a lo largo de los años siguientes. Los representantes diplomáticos italianos manifestaban, a comienzos de 2002, que, desde el 20 de diciembre del año anterior, atendían aproximadamente a 800 personas por día y que, a partir de entonces, el número se había triplicado ${ }^{8}$. En 2002 se otorgaron 43.000 ciudadanías; 75.000, en 2003; mientras que en 2004 el número disminuye, no obstante aún la cifra alcanzada supera al de 2002, 44.500 personas la obtuvieron ${ }^{9}$.

Sin embargo, no fueron los únicos. Inclusive los consulados de países del Este, que a partir del 1..$^{\circ}$ de mayo de 2004 se incorporarían a la Unión Europea, vieron crecer las solicitudes de recuperación de nacionalidad.

El cónsul de Estonia, Peet Pullisaar, declaraba: «Florecieron estonianos como hongos. Teníamos registros de 130, pero somos muchos más, 200 por lo

3 No hay estadísticas que reflejen la edad de los que emigran de Argentina, sin embargo, en el caso español, se recoge este dato: el $40 \%$ de los empadronados a $1 .^{\circ}$ de enero de 2007 , nacidos en Argentina, se encontraban en la franjas etarias de 20 a 34 años. Instituto Nacional de Estadística, 2007.

${ }^{4}$ El aeropuerto internacional de Buenos Aires, Ministro Pistarini, se encuentra ubicado en el municipio de Ezeiza, siendo éste el nombre por el que se lo conoce popularmente.

5 Página 12 (Buenos Aires, 25 de febrero, 2002).

6 Página 12 (Buenos Aires, 17 de febrero, 2002).

7 Página 12 (Buenos Aires, 26 de enero, 2002).

8 «Cuando emigrar se convierte en una cuestión cultural». Página 12 (Buenos Aires, 25 de febrero, 2002).

9 «Un 45\% más de argentinos se fueron del país el año pasado». La Nación (Buenos Aires, 29 de mayo de 2005). 
menos. Pero ya no les interesa Estonia, les interesa el pasaporte europeo. Llama gente que jamás mantuvo relación con la colectividad. En algunos casos, los resultados fueron positivos. En otros, no; no poseían documentación y además porque los interesados deben viajar a Estonia y tramitar la ciudadanía allí»» ${ }^{10}$. $\mathrm{O}$ el testimonio del representante polaco, Jaroslaw Grabowiecki, para quien: «Muchos quieren volver a Polonia. Y muchos otros ser europeos. Algunos vienen con papeles que creen documentos, pero como no hablan ni leen polaco desconocen que lo que traen son las cuentas de un zapatero. Pero no es nuestro papel juzgar las motivaciones. Más allá de su religión o etnia, si acreditan su condición de polacos debemos darles la ciudadanía» ${ }^{11}$.

Ahora bien, si esto ocurría en relación a países que aún no formaban parte de la Unión Europea, en aquellos que ya lo eran de pleno derecho, como ocurría con España, la situación fue más extrema, las personas se agolparon por millares delante de sus consulados. Los que intentaron recuperar la nacionalidad de los antepasados españoles fueron muchos, no olvidemos que esta inmigración fue - junto a la de italianos - la más numerosa en Argentina, llegando a alcanzar, entre 1880 y 1930 , la cifra de 1.594 .822 personas $^{12}$. El volumen de solicitudes de nacionalidad de ese origen pasó de alrededor de 5.000 individuos en 1997, a duplicarse cuatro años más tarde.

Es necesario indicar que una nueva legislación, vigente desde el 9 de enero de $2003^{13}$, facilitó la tramitación a un buen número de personas mayores de 18 años, con padres de origen español, pues hasta entonces sólo podían solicitarla los que no hubiesen alcanzado tal edad. Todo ello contribuyó para que entre los años 2000 y 200514, 93.246 argentinos lo lograran. En especial, el período comprendido entre 2002 y 2005 es el más importante en cuanto al volumen de personas que accedieron a la nacionalidad española, ya que en esos años 72.440 individuos la recuperaron.

Conseguido un pasaporte europeo, por lo general no se emigra al país que lo ha emitido. En la mayoría de los casos se trata de familiares que - como indicaba el cónsul de Polonia refiriéndose a los descendientes de esa nacionali-

10 «Más argentinos que podrán ser europeos (parte 2.a ). Descienden de países que integrarán la UE». El Clarín (Buenos Aires, 13 de enero de 2003).

11 Idem.

12 En el mismo periodo los italianos fueron 2.325.025. González Martínez, CLIV (Madrid, julio de 1996): 18.

13 Se trata de la reforma del artículo 20 del Código Civil, aprobada en octubre de 2002 y vigente desde el 9 de enero de 2003.

${ }^{14}$ Las estadísticas acerca de nuevas nacionalizaciones y bajas consulares por traslado a España nos fueron facilitados por el entonces Cónsul General de España en Buenos Aires, don Manuel Fairen Sáenz, con quien estamos en deuda. 
dad, pero que puede ser extrapolable a otras - no dominan el idioma de sus ancestros, ni tampoco guardan las tradiciones, sólo pretenden residir en Europa. Muchos, como se refleja en un registro estadístico español, no se trasladaron al país de sus abuelos ${ }^{15}$.

En efecto, en el padrón de habitantes de los municipios españoles, en 2007, se detecta que, además de las 86.567 personas nacidas en Argentina pero que poseen la nacionalidad española, existen 47.122 que disponen de alguna europea. Entre otras, por ejemplo, 42.120 personas nacieron en Argentina aunque tienen pasaporte italiano, 1.933 alemán y 860 francés $^{16}$.

Cuadro 1. España. Volumen de población empadronada, argentina de nacimiento con OTRA NACIONALIDAD (Año 2007)

\begin{tabular}{|l|r|}
\hline Nacionalidad española & $\mathbf{8 6 . 9 5 3}$ \\
\hline Nacionalidad europea & $\mathbf{4 7 . 2 3 1}$ \\
\hline Alemania & 1.944 \\
Bélgica & 264 \\
Bulgaria & 3 \\
Francia & 866 \\
Italia & 42.198 \\
Países Bajos & 185 \\
Polonia & 89 \\
Portugal & 278 \\
Reino Unido & 331 \\
Rumanía & 6 \\
Rusia & 1 \\
Suiza & 149 \\
Ucrania & 0 \\
Resto de nacionalidades de Europa & 917 \\
\hline Nacionalidad argentina & $\mathbf{1 3 7 . 8 3 7}$ \\
\hline Resto nacionalidades & $\mathbf{9 6 4}$ \\
\hline Total & $\mathbf{2 7 2 . 9 8 5}$ \\
\hline
\end{tabular}

Fuente: Elaboración propia con base en datos del INE, 2007.

15 En un estudio realizado por Susana Novick a una muestra de 55 argentinos residentes en el extranjero, se revela que la nacionalidad y el país de residencia no tienen por qué ser los mismos. Los que tienen un pasaporte español están radicados en España; los que cuentan con uno italiano pueden hacerlo en Italia, España, Francia, Inglaterra y Canadá; y aquellos con nacionalidad alemana, francesa e israelí viven en Alemania, España e Israel. Novick, s/d.: 27.

16 Instituto Nacional de Estadística, 2007. 
Estas cifras sin duda muestran la atracción que España profesa sobre los argentinos, tengan o no vínculos familiares previos. El ejemplo más notorio es el de las más de 40.000 personas que podrían haberse encaminado hacia Italia, ya que de allí necesariamente provenía un antepasado, pero se establecen en España en donde como es obvio, compartir el mismo idioma es un aliciente poderoso. Para otros, no es el único atractivo, hay un vínculo más directo. Casi la mitad de la población desciende de españoles, en la memoria de muchas familias está presente aquello que tuvieron que abandonar, en otras inclusive se mantienen contactos con los familiares que permanecieron del otro lado del Atlántico, siendo en ese momento cuando no pocos argentinos descubren su origen y el poder de atracción que éste ejerce.

Pero tampoco se trata sólo de afinidades culturales, que sin duda en este caso son múltiples, y que podríamos sintetizar en el hecho ya señalado de una lengua en común, sino de algo más profundo que se relaciona con el día a día de las personas.

Los argentinos, dada la cultura migratoria con la que cuenta la mayoría, se sienten europeos, entienden que comparten un conjunto de valores. Por ello es que antes de emigrar piensan que en España no se van a encontrar en un lugar muy ajeno, que la cercanía cultural y simbólica es un hecho. Sintetizando, no se ven «tan diferentes». La visión cambiará en el momento en que se instalen en el nuevo país, aunque esto nos remite a otra temática ${ }^{17}$.

\section{LAS «FACILIDADES» PARA EMIGRAR DE LOS ARGENTINOS}

Al parecer el componente emigratorio forma parte de la «condición» de ser argentino. En las entrevistas se repite el argumento de que en sus genes se encuentra la posibilidad de emprender ese camino en algún momento. Damos el ejemplo de dos testimonios obtenidos de fuentes diferentes, en un caso de la entrevista realizada al padre de dos hermanos residentes en Madrid, en otro la opinión vertida por el participante en un foro, ambos coinciden en manifestar que el hecho migratorio integra al propio individuo. El padre de los emigrantes piensa que, «Esa circunstancia de emigración está en la familia (...), digo, quizás sea eso, hay un "imprinting" o un hecho genético de alguien que tiene más capacidad de movilidad» ${ }^{18}$. Para el otro: «¿Cómo puede ser que la idea de que

17 González Martínez, 2008: 329.

18 Entrevista realizada en Buenos Aires a Rodrigo, padre de emigrantes. 59 años, Biólogo. Citado en González Martínez, 170/XLV (Roma, aprile-giugno 2008): 324. 
ir a Europa era salvarse se haya propagado tan rápido? Creo que está inscrita en nuestros genes» ${ }^{19}$.

El relato de sus mayores les había hecho conocer a la España de la primera mitad del siglo XX. Con la estabilidad política y social alcanzada a partir de la transición democrática, la incorporación a la Unión Europea y el desarrollo económico que experimentó en las últimas décadas del milenio, otra España emergía.

En otros planos hay factores que también contribuyen. Para un argentino no es demasiado complejo el acceso a España, sin embargo la situación varía cuando pretende obtener la documentación que le permita ser un inmigrante «regular». Para entrar al país sólo es necesario contar con el pasaporte, acompañado del seguro de enfermedad, una reserva de hotel o carta de invitación donde se informa el alojamiento particular que se va a utilizar, un monto de dinero que se calcula relacionándolo a los días de permanencia en el país y el billete de regreso. Los argentinos, junto a los uruguayos, brasileños y chilenos, tienen en ese sentido un estatus privilegiado, ya que no se les exige un visado de turistas, como sucede en cambio con el resto de los latinoamericanos. Por otra parte, tal como es destacado por los propios inmigrantes, su apariencia «europea» les facilita el pasaje por el control de inmigración de los aeropuertos ${ }^{20}$.

No obstante lo que hemos ido señalando, consideramos que el factor clave que determina que un individuo decida encaminarse a un lugar y no a otro es la existencia de redes sociales consolidadas. El papel que ellas desempeñan es fundamental ya que se responsabilizan por la construcción de los vínculos necesarios para la emigración. Más aún, creemos que tienen un efecto multiplicador, porque las redes ayudan a reducir los costos, por ello entendemos no sólo los materiales, sino los emocionales ${ }^{21}$.

Las redes - que pueden ser de distinto tipo: familiares, amicales o simplemente de paisanaje- independientemente del grado de intensidad que alcancen los lazos, existen y a través de ellas se estructura un verdadero circuito, en el que circulan las informaciones y percepciones de los que ya han marcha$\mathrm{do}^{22}$. Respecto a los argentinos, la presencia de una inmigración previa en

19 Extraído de: http://www.andaos.blogspot.com/2007/01/discriminacion-o-la-venganzadel-bolita.html. Enviado por Retros el 20 de enero de 2007.

20 González Martínez, 330 (Roma, 2008).

21 Arango, 165 (UNESCO, 2000).

22 Utilizamos el concepto de red social tal como es definido por Douglas Massey, es decir el conjunto de vínculos interpersonales que relacionan a los emigrantes con quienes los han precedido en el mismo camino y con los que no lo han hecho, a través de lazos de parentesco, amistad o paisanaje. Massey, 1999. 
España en la década de los noventa, que aunque cuantitativamente menor a la actual, importante por el hecho de que, ella y los remanentes del exilio de 1976, formaron las redes iniciales que constituyen el embrión de las que se configuran en el presente.

En plena crisis — mayo de 2002 - se realizó una encuesta ${ }^{23}$ que mostró cómo más de la mitad de las personas que habían escogido marchar a España contaban con algún contacto en el país y ello había sido determinante para la elección.

El viaje podía realizarse en solitario, pero los jóvenes emigrantes argentinos de este siglo, al llegar, se encontraron con amigos de sus padres, amigos suyos o amigos de sus amigos, tíos o primos, vecinos, compañeros de trabajo o simplemente alguien relacionado con su entorno. De ellos recibieron información valiosa y en muchos casos alojamiento durante los primeros días de estancia en España. Utilizaremos el ejemplo de lo que ha sucedido con la emigración a Baleares, en particular a Palma de Mallorca.

\section{EL COMPONENTE INMIGRATORIO EN BALEARES}

La magnitud que ha alcanzado el fenómeno inmigratorio en Baleares queda de manifiesto cuando observamos las cifras. Mientras que en 1996 vivían en las islas 30.709 extranjeros, en 2007 el número se elevó hasta alcanzar a 166.936 personas, que representa un incremento del $543.6 \%$, en sólo poco más de una década. Otra cuestión a destacar es el componente migratorio, en 1996 el 74,1\% procedía del espacio europeo, sin embargo, en 2007, la proporción se redujo al 48,1\%, mientras que los latinoamericanos, que en la década de los noventa prácticamente no estaban representados, ocupan el segundo lugar, con el $27,2 \%{ }^{24}$.

Tal volumen de inmigrantes hace que las Baleares tengan el porcentaje de extranjeros más elevado de España (15,8\%), buena parte de ellos provienen de países como Alemania y Gran Bretaña. Se trata de jubilados que llegaron en las últimas décadas del siglo pasado buscando mejorar su calidad de vida y un clima benigno. Paralelamente arribó también población joven que se incorporó al mercado de trabajo, aprovechando las actividades comerciales que iba generando la estancia de los anteriores.

${ }^{23}$ La encuesta, realizada por la Universidad de Ciencias Empresariales y Sociales a 300 personas residentes en la Capital Federal y su cono urbano, también señalaba que el $22 \%$ de los consultados tenía planeado irse del país. Página 12 (Buenos Aires, 17 de mayo, 2002).

24 Direcció General d'Immigració, 2008: 10-11. 
Al igual de lo que ocurría en el resto de España, los latinoamericanos comenzaron en la última década a participar de este tipo de flujo. En este conjunto la nacionalidad más numerosa es la argentina que representa el 10\% del total de extranjeros, a continuación se encuentra la ecuatoriana y, en tercer lugar, la colombiana.

Según el Instituto Balear de Estadísticas (IBAE) la evolución de la población argentina es la siguiente:

Cuadro 2. Número de argentinos empadronados en Baleares ${ }^{25}$

\begin{tabular}{|c|c|}
\hline Año & Individuos \\
\hline 1999 & 1.102 \\
2000 & 1.393 \\
2001 & 2.649 \\
2002 & 5.027 \\
2003 & 9.148 \\
2004 & 10.426 \\
2005 & 11.195 \\
2006 & 10.802 \\
2007 & 11.129 \\
\hline
\end{tabular}

Fuente: Elaboración propia con base en datos del IBAE.

El millar de residentes en 1999 no es cuantitativamente muy significativo. Sin embargo, a partir de entonces, en paralelo a la profundización de la crisis político-económica de Argentina, se produjo un aumento en el número de los que llegan. Los flujos se dinamizan, tanto en las Baleares, como en diversos puntos de la península y en Canarias.

Ocho años más tarde el número de personas empadronadas ha crecido alcanzando la cifra de 11.129 al $1 .^{\circ}$ de enero de 2007 , que representan el $10 \%$ del total de población extranjera de la isla. Aunque debemos tener presente que el incremento es aún más importante si incluimos a las que, habiendo nacido en Argentina, disponen de otra nacionalidad.

Al igual que para el conjunto de España, la existencia de argentinos con nacionalidad italiana es muy elevado, representan casi el $17 \%$ del total de los que nacieron en Argentina, mientras que los que han obtenido la española rozan el $22 \%$.

25 Institut Balear d'Estadística, 2007. 
Cuadro 3. Padrón de habitantes de Baleares. Personas nacidas en Argentina según NACIONALIDAD $(2007)^{26}$

\begin{tabular}{|l|c|}
\hline \multicolumn{1}{|c|}{ Nacionalidad } & Empadronamientos \\
\hline Argentina & $10.887^{27}$ \\
Alemana & 225 \\
Española & 5.311 \\
Francesa & 65 \\
Italiana & 4.740 \\
Portuguesa & 27 \\
Reino Unido & 32 \\
Otras & 409 \\
\hline Total & 21.471 \\
\hline
\end{tabular}

La mayoría de los inmigrantes argentinos son jóvenes, especialmente se concentran en la franja etaria de los 25 a los 29 años:

Cuadro 4. Evolución de la población de nacionalidad argentina en Baleares según LA EDAD Y SEXO ${ }^{28}$

\begin{tabular}{|l|r|r|r|r|r|r|r|r|}
\hline \multicolumn{1}{|c|}{ Edad } & \multicolumn{2}{|c|}{ Año 2004 } & \multicolumn{2}{c|}{ Año 2005 } & \multicolumn{2}{c|}{ Año 2006 } & \multicolumn{2}{c|}{ Año 2007 } \\
\hline & \multicolumn{1}{c|}{ H } & \multicolumn{1}{c|}{ M } & \multicolumn{1}{c|}{ H } & \multicolumn{1}{c|}{ M } & \multicolumn{1}{c|}{ H } & \multicolumn{1}{c|}{ M } & \multicolumn{1}{c|}{ H } & M \\
\hline Total & 5.358 & 5.068 & 6.116 & 5.799 & 5.508 & 5.294 & 5658 & 5471 \\
$20-24$ & 517 & 512 & 476 & 487 & 418 & 441 & 456 & 455 \\
$25-29$ & 1.117 & 1.050 & 1.210 & 1.145 & 1.026 & 1004 & 963 & 984 \\
$30-34$ & 893 & 708 & 1.090 & 870 & 1.018 & 857 & 1078 & 966 \\
\hline
\end{tabular}

26 Idem.

27 Existe una diferencia entre los datos que brinda el Instituto Nacional de Estadística y el Instituto Balear de Estadística para el año 2007. Mientras que el primero señala que están empadronados en Baleares 11.129 argentinos, las fuentes de las islas señalan algunos menos, en total: 10.887 .

28 Institut Balear d'Estadística, 2007. 
La ya señalada concentración en esos segmentos subraya el hecho de que la emigración argentina, corroborando lo que señalamos al comienzo del texto, está integrada en gran parte por jóvenes, aunque es semejante - también hay que indicarlo - a la del conjunto de extranjeros, de tal manera que en Baleares uno de cada cinco jóvenes es inmigrante ${ }^{29}$.

Su distribución en las islas no es homogénea, fundamentalmente se concentran en una de ellas, Mallorca. Allí vive el 80,09\% de los argentinos, por detrás se sitúa Ibiza con el 13,34\%, Menorca, con el 5,02\% y, finalmente, Formentera, que reúne el $1,54 \%{ }^{30}$. Habría que recordar que Palma, por su oferta habitacional y sus ofertas de trabajo había sido escogida por el $45 \%$ de los argentinos en $1996^{31}$, justamente entendemos que, con ellos, se inició la red que permitió el intercambio de información a estos nuevos migrantes argentinos del siglo XXI.

\section{LOS MARPLATENSES EN MALLORCA}

No es posible conocer con exactitud de dónde son oriundos. Sin embargo, las entrevistas que hemos realizado y diversas informaciones tanto del ámbito periodístico como académico, indican que, aunque provienen de localidades pertenecientes a distintas provincias argentinas, un alto porcentaje es originario de la ciudad de Mar del Plata y de su área de influencia. Los testimonios dan cuenta que allí se generó un boca a boca que permitió la formación de redes, con resultados muy efectivos, tanto es así que al parecer el $70 \%$ de la emigración de esta localidad turística argentina escogió Mallorca y no otro lugar en las Baleares ${ }^{32}$. «En 2002, ¿quién no conocía a alguien que se había ido a España? Media Mar del Plata estaba en Mallorca ${ }^{33} »$, nos relató uno de nuestros entrevistados. Además los residentes en Baleares autoperciben la gran afluencia de marplatenses. El presidente de la Casa Argentino Balear de Pal-

29 «Uno de cada cinco jóvenes que reside en Baleares es extranjero, un 30\% más que la media española». El Mundo/El día de Baleares (Domingo, 11 de febrero de 2007).

30 Institut Balear d'Estadística, 2007.

31 En 1996 había 952 argentinos empadronados en Mallorca, de los cuales 400 lo estaban en el ayuntamiento de Palma de Mallorca. Institut Balear d'Estadística, 2007.

32 Ver al respecto el artículo «Mallorca la isla de la fantasía». Página 12 (Buenos Aires, 25 de mayo de 2003). También: «Revolución sociológica en Baleares II. La colonia argentina. "Que nos van a decir a nosotros si somos nietos de españoles». El Mundo. Suplemento de Baleares. (Palma de Mallorca, 21 de octubre de 2002).

33 Entrevista realizada a Daniela, casada con español, 30 años de edad, llegó a Mallorca en 2000, estudios de esteticista. 
ma, calculaba que más de una tercera parte de todos los inmigrantes argentinos de las islas, proceden de Mar del Plata, especificando que especialmente la juventud de esa ciudad se trasladó a Baleares ${ }^{34}$.

¿Por qué la emigración argentina elige Mallorca? ¿Qué llevó a los pioneros a escoger este destino en las Baleares?

En primer lugar hay que destacar las características geográficas y económicas de la isla, que son semejantes a las de Mar del Plata ${ }^{35}$. En esta ciudad, al otro lado del Atlántico, residen 541.733 personas $^{36}$, sin embargo, en verano o en períodos de vacaciones invernales, se produce un notorio incremento de población que genera una mayor oferta de bienes y servicios.

El mercado de trabajo marplatense se caracteriza por encontrarse fuertemente concentrado en actividades ligadas al turismo masivo ${ }^{37}$. Durante la crisis económica que hemos señalado, dichas actividades —en especial la hostelería y la restauración, pero también el comercio, la industria manufacturera y textil ${ }^{38}$, etc. - , mostraron una fuerte caída en términos de empleo ${ }^{39}$, afectando el paro al $24,6 \%$ de su población económicamente activa, casi un $3 \%$ más elevado que el porcentaje de la media nacional ${ }^{40}$. Además de esta alta tasa de desocupación se podía apreciar un gran deterioro en los salarios y las relaciones laborales, que a la vez que aumentaba la precariedad laboral extendía el trabajo informal ${ }^{41}$.

A su vez, Mallorca tiene 790.763 habitantes, de los cuales más de la mitad, 404.335, se encuentran concentrados en Palma. Del mismo modo que en el caso anterior, su población se multiplica por la llegada de millones de turistas para la temporada veraniega. El impacto de la estación estival se hace notar también en la hostelería y el comercio en general, demandando un número extra de mano de obra.

Los parecidos son señalados en las entrevistas que hemos realizado. Algunos se refieren a las características del emplazamiento de ambas ciudades: «Y yo creo que uno cuando sale... quieras que no, buscás un poquito algo con lo

34 Idem.

35 Ciudad ubicada al 404 kilómetros al sudeste de la Capital Federal, pertenece al municipio de General Pueyrredón.

36 INDEC. Censo Nacional de 2001.

37 Sobre el desarrollo turístico de Mar del Plata y su transformación en el balneario escogido mayoritariamente por los argentinos: Torre y Pastoriza, 1999: 49-77.

38 Mar del Plata tiene una fuerte industria ligada a la ropa de lana. Concomitantemente abundan los comercios dedicados a la venta de jersey, vestidos, además de cazadoras, etc.

39 Mazorra y otros: http://www.aset.org.ar/congresos/7/09002.pdf

40 Grupo de Estudios del Trabajo, 2008: 10.

41 Gallo, 9/16 (Mar del Plata, 2003): 111. 
que sentirte identificado. Poder salir a la calle, ver el mar, todas esas cosas pues te hacen sentir un poquito más en casa que si estuviera viviendo en Madrid por ejemplo. Que igual estaría bárbara también en Madrid, pero... el ritmo de vida... a mí me gusta mucho Palma porque me hace acordar mucho a mi ciudad $\left.{ }^{42}\right\rangle$.

«En Palma salís y el mar está cerca siempre... igual que en Mar del Plata, tal vez la diferencia esté en el tiempo, el invierno en Mardel es mucho más frío, bueno y el verano también ${ }^{43} \gg$.

«Mar del Plata y Palma son casi iguales, si hasta Mallorca tiene la Tramuntana, como en Mar del Plata está la sierra de la Ventana....44».

«Palma es casi igual a Mar del Plata, tienen casi el mismo tamaño, tienen el mar, se llenan de gente en verano. Lo diferente es que es una isla... ${ }^{45}$ ».

Otros describen las similitudes entre sus mercados laborales:

"A mí me enganchó mucho eso; yo creo que en cierto aspecto esto se parece mucho a Mar del Plata. Tiene un verano muy fuerte de trabajo... $\left.{ }^{46}\right\rangle$.

Aunque la mayoría se refiere a la presencia de «paisanos» de su ciudad:

«Mallorca es como estar en Mar del Plata, pateás una piedra y salen marplatenses... ${ }^{47} \gg$.

«Estamos por todas partes, si vas a la playa te encontrás con alguien de Mardel, si te vas a un café el mozo es marplatense y así todo ${ }^{48} . . . »$.

Respecto al mercado de trabajo, teniendo en cuenta las características señaladas, existe una alta tasa de estacionalidad laboral, en Mallorca el sector servicios concentra la mayoría de los puestos de trabajo (75\%), la construcción queda muy por detrás, con el $14 \%$, la industria $9 \%$ y el sector primario, $2 \%{ }^{49}$.

42 Entrevista realizada a Beatriz, 27 años, casada, llegó a Mallorca en 2002, estudios universitarios incompletos, pasaporte comunitario.

43 Entrevista realizada a Juan, 26 años, soltero, llegó a Mallorca en 2001, formación profesional, pasaporte comunitario.

44 Entrevista realizada a Susana, 44 años, divorciada, llegó a Mallorca en 2004, estudios de grado medio, permiso de residencia y de trabajo.

45 Entrevista realizada a Pedro, 32 años, casado, estudios de grado medio, llegó a Mallorca en 1998, nacionalidad española.

46 Entrevista realizada a Javier, 32 años, casado, llegó a Mallorca en 1999, estudios de grado medio, nacionalidad italiana. Citado en González Martínez y Merino Hernando, 2007: 106.

47 Entrevista realizada a Lucía, 32 años, en pareja, estudios universitarios incompletos, llegó a Mallorca en 2001, nacionalidad italiana.

48 Entrevista realizada a Daniel, 58 años, casado, llegó a Mallorca en 2001, estudios secundarios, nacionalidad española.

49 Conselleria d'Economia, Hisenda i Innovació, s/d.: 16. 
La gran demanda laboral fue un factor de atracción tan poderoso como el paisaje marítimo que comparten. Aun antes de la crisis, los más jóvenes, empezaron a trasladarse a Palma durante la temporada invernal de su ciudad natal. De esta manera combinaban el invierno austral con el verano europeo. De mayo a octubre permanecían en Mallorca, el resto del año lo hacían en Mar del Plata. Contaban con una amplia experiencia en actividades ligadas al turismo, la mayoría había trabajado en hoteles, restaurantes, bares, etc. «En Mar del Plata trabajo desde los 15 en temporada, todos los veranos de mi vida. En invierno, a medida que fui estudiando, trabajaba. Pero soy de temporada. Y llegué acá, hice la temporada, viajé, me fui a Argentina, vine, hice la temporada. Y este año dije bueno... quería venir en invierno para ver cómo es esto en invierno ${ }^{50}$ 》.

Como se desprende de éste, y del testimonio de otros entrevistados, los viajes se repetían, las ganancias obtenidas en el período veraniego les permitía pagarse el pasaje, mantenerse en la isla y ahorrar lo suficiente para regresar a Mar del Plata con dinero para vivir el resto del año. Son los trabajadores «golondrinas» del siglo XX, claro que ahora no ayudan en las cosechas, sino que - aún sin papeles - se desempeñaban trabajando en el sector servi$\operatorname{cios}^{51}$.

Justamente el comportamiento similar del mercado de trabajo es el factor que imprime más carácter en los flujos migratorios a Baleares. El fenómeno que se produce, que algunos argentinos llegan a las islas y regresan a su país, para retornar al cabo de un año, no es algo común en la península. Es difícil evaluar con precisión la magnitud de la población incluida en este tipo de actuación. Como es obvio no involucra a todos los inmigrantes, pero es necesario señalar que para algunos ellos los desplazamientos constituyen la forma habitual de ganarse la vida, dividiendo el año laboral en dos partes, una situada en las orillas del Atlántico, la otra en el Mediterráneo.

El siguiente es un ejemplo de este tipo de proceder: «Hace tres años que venimos, hacemos temporada de verano acá y temporada de verano en Mardel, como Juan es guardavidas, nos lo manejamos de esa forma ${ }^{52}$ ».

50 Entrevista realizada a Julián, 34 años, casado, llegó a Mallorca en 2001, estudios universitarios, nacionalidad española.

51 Los argentinos se caracterizan por incorporarse al mercado de trabajo urbano. En el medio rural es difícil encontrar alguno, sólo el 0,6\% de las altas de trabajadores argentinos en la Seguridad Social, al 31 de diciembre de 2007, estaban dadas en el sector agrario. Pajares, 2008: 53 .

52 Se trata de los socorristas. Este caso, y el de los entrenadores de esquí, son dos profesiones cuyos trabajadores reparten su año laboral entre Argentina y España. 
Esta emigración «golondrina» fue imprescindible para que se fortalecieran las redes sociales existentes. Un individuo que regresa cada año, relata cómo le ha ido, esa información se transmite y multiplica, de manera que el círculo de personas que la recoge va ampliándose. Además se trata de información positiva hacia el lugar al que se emigró, de otra manera no repetirían la experiencia; este hecho es muy claramente percibido por los que la obtienen. Las narraciones incluyen cuestiones relacionadas con el salario y el coste de vida, cuánto dinero se puede ahorrar, o las «virtudes» de la isla, además la persona que recibe la información interroga acerca de aspectos prácticos, cómo encontrar vivienda, trabajo, cuáles son los mejores barrios para residir, una cantidad de asuntos puntuales y diversos, que le preocupa, por ejemplo, sobre la escolarización de los hijos, o cómo es la cobertura sanitaria, etc. Este bagaje de conocimientos les permitirá formar un capital social que facilitará no sólo la toma de decisión, sino posteriormente el asentamiento en el lugar de destino. Momento éste en el que la intervención solidaria de algún miembro de la red se convierte en algo fundamental.

Ahora bien, la pregunta que surge es cuándo comienza a generarse la red. En el caso de Baleares, habría que señalar que ya desde las últimas décadas del anterior milenio podía detectarse la presencia de residentes argentinos. Algunos estaban instalados a raíz del exilio en los años setenta, no pocos eran descendientes de mallorquines que optaron por «retornar» a la tierra de los abuelos ${ }^{53}$ y otros llegaron expulsados por la hiper inflación de la década de los noventa. Fue a partir de ese núcleo que se fue gestando la red de contactos, construyéndose una infraestructura social entre el lugar de origen y el de destino, que activó la circulación de personas, posibilitando que se transformase el hecho individual en un proceso mucho más masivo ${ }^{54}$.

El discurso de todos se asemeja en cuanto a que coinciden en manifestar que contaban con algún vínculo en la isla ${ }^{55}$. Los testimonios son unánimes al respecto, cada uno, no importa el sexo del entrevistado, tampoco la edad, tenía la referencia de alguien que ya residía en Mallorca. Este elemento es fundamental, de esta manera pueden abaratarse los costos emigratorios. Unos dicen:

53 Jofre, 2003.

54 Sobre red de contactos ver: Parrados, 1992.

55 En el trabajo de S. Novick un 92,2\% tiene algún tipo de vínculo en el sitio a donde piensa emigrar.

Novick, s/d: 32 .

Otro artículo, centrado en las causas de la emigración de marplatenses, señala que la existencia de contactos en el lugar de llegada es una constante. El 25\% de la muestra contaba con una promesa de trabajo; el 75\% con un lugar donde acogerse; el 87,5\% disponían de ayuda o de alquien que los introdujera en Mallorca. Rodríguez López, 9/16 (Mar del Plata, 2003): 22. 
«Todos traíamos un teléfono de allá, de conocidos, conocidos no, la mayoría de la gente no la conocíamos... eran de la oleada de los ochenta ${ }^{56} »$; Otros: «Teníamos gente conocida, gente de Mar del Plata que sabía que se había venido para acá. Entonces bueno... a ver... bueno, nos hicimos de esos amigos acá, más que amigos allá, eran conocidos allá ${ }^{7} \gg$.

Para un tercero el contacto fue: «mi tía, estaba mi tía y mi abuela estaban acá desde la dictadura... $\left.{ }^{58}\right\rangle$.

Juan nos contó que, «se vino Leo (su amigo) y yo me recibí (se graduó), vine a verlo de vacaciones. Una vez que planteé que iba a hacer... y me vine ${ }^{59}$ ».

Andrea tomó la decisión porque «en Mar del Plata no se hablaba de otra cosa que de Mallorca, y dos compañeras del colegio se habían venido» ${ }^{60}$.

La presencia de amigos — en este caso en concreto y dada la juventud de los emigrantes, en especial de antiguos compañeros de colegio- mucho más que la de familiares, se repite en los testimonios, todos, insistimos, contaban con alguna persona que había llegado antes que ellos. Al comienzo de la trayectoria migratoria reciben de ellos información, mucho ánimo —en algún caso les dicen muy a las claras: «venite que acá ya nos vamos a arreglar»—, alojamiento los primeros días y orientación para encontrar tanto empleo como una vivienda.

Esa red que como es obvio tiene que existir previamente a que se produzca la emigración, se activa al llegar, y aunque en muchos casos implique la existencia de lazos débiles, transcurrido poco tiempo se convierte en un tejido muy tupido y dinámico, sus componentes van incrementándose a la vez que se establecen relaciones fuertes. Inclusive, a medida que pasan los meses, puede ampliarse e incluir a personas de diferentes nacionalidades.

Mientras que en otros colectivos inmigrantes latinoamericanos concurrir a alguna institución étnica o asistencial en busca de alojamiento y trabajo es algo habitual - especialmente relevante es el papel que desempeñan ciertas parroquias y las iglesias evangélicas_- en el caso de los argentinos no hemos encontrado testimonios que señalen, a su llegada a la isla, un comportamiento

56 Entrevista realizada a Pedro, 32 años, casado, estudios de grado medio, llegó a Mallorca en 1998, nacionalidad española.

57 Entrevista realizada a Beatriz, 29 años, casada, estudios universitarios incompletos, llegó a Mallorca en 2002, nacionalidad sueca.

58 Entrevista realizada a Lucía, 32 años, en pareja, estudios universitarios incompletos, llegó a Mallorca en 2001, nacionalidad italiana.

59 Entrevista realizada a Juan, 31 años, casado, estudios de grado medio, llegó a Mallorca en 2002, nacionalidad española.

60 Entrevista realizada a Daniela, 28 años, casada, estudios secundarios, llegó a Mallorca en 2000 , permiso de residencia y de trabajo. 
de ese tipo. Más tarde pueden hacerlo, allí encuentran asesoramiento y un espacio de ocio ${ }^{61}$.

Respecto al trabajo, aunque acuden a internet para consultar las empresas de trabajo temporal y a los anuncios en periódicos, en especial el Trueque, sobre todo funciona el boca a boca. Nuevamente se acude a la red social buscando una solución. Por ejemplo una cuestión importante tiene que ver con la fecha de llegada a la isla. Los testimonios son coincidentes en ese sentido, les habían dado la clave de la fecha en que debían hacerlo, el arribo debe producirse en primavera, momento en que aumenta la oferta laboral.

Algunos, los más afortunados, inclusive ya contaban con un empleo al llegar: «Me vine en abril y mis amigos me habían conseguido un curro, empecé a la semana a trabajar de camarero ${ }^{62} 》$; "Cuando llegué tenía un trabajo, un compañero del colegio trabajaba en un restaurante, a los tres días me fui con él, como pinche de cocina ${ }^{63}$ »).

Contar con un empleo antes de viajar, o conseguirlo al establecerse en Mallorca, en ambos casos, insistimos, es alguien que los conoce quien lo facilita. «Fue Juan, con quien vine a vivir recién, recién aterrizado, él me llevó a una disco, trabajé 5 horas de 8 a 1, ni tenía papeles, ni nada ${ }^{64}$ ». O: «a uno de los chicos le dieron el teléfono... de uno que era muy amigo del papá, del tío, no sé qué... estaba el negro ahí... a él lo conocía de chiquito. Lo llamamos y... nos dio trabajo, es una gente que se portó bien, muy bien ${ }^{65}$ ».

Ahora bien, lograda la meta de tener una ocupación, vemos cómo se va cambiando con mucha rapidez de empleo. Una de las características comunes que hemos observado entre las personas entrevistadas es la alta rotación en la ocupación. Aunque también en este caso el papel de la red es fundamental

Pedro trabajó al llegar seis meses como camarero, de allí pasó a ocuparse del mantenimiento de una disco, más tarde se desempeñó como pinche en el

61 Existen varias asociaciones que los agrupan. Un grupo de ellas se han reunido en una federación denominada «Casal Argentino de les Illes Balears», que brinda orientación legal - en especial les facilita el trámite de obtener una cita — cuando necesitan sus servicios - en el consulado argentino en Barcelona, del cual dependen los residentes argentino en Baleares, cursos de capacitación laboral, una bolsa de trabajo, etc. Entrevista realizada a su presidente, señor Héctor Marano, a quien agradecemos su buena disposición.

62 Entrevista realizada a Mariano, 29 años, en pareja, llegó a Mallorca en 2001, estudios secundarios, pasaporte español.

63 Entrevista realizada a Raúl, 31 años, en pareja, llegó a Mallorca en 2002, estudios universitarios, pasaporte italiano.

64 Entrevista realizada a Daniel, 32 años, en pareja, llegó a Mallorca en 2003, estudios de formación profesional, permiso de trabajo y residencia.

65 Entrevista realizada a Guillermo, 29 años, soltero, llegó a Mallorca en 2001, estudios secundarios, permiso de trabajo y residencia. 
restaurante de un hotel, de este empleó saltó a otro, donde trabajaba como comercial en un lugar de venta de recuerdos de Mallorca, finalmente otra vez su ocupación tiene que ver con en el mantenimiento de un hotel, en donde todavía permanece. Salvo cuando fue pinche de cocina, empleo al que llegó por un aviso en el periódico, el resto de ellos fue conseguido porque alguien le informó de la vacante. Como vemos, en todos los casos se trata de ocupaciones que requieren escasa cualificación, aunque en lo que se refiere a Pedro, éste contaba con una instrucción que le permitiría acceder a otras mas acordes con su formación —realizó estudios de grado medio, especializándose en contabilidad comercial — . Sin embargo, se adapta a los requerimientos del mercado, aunque no renuncia a aspirar algo en lo que se encuentre valorado por la formación y experiencia con que cuenta.

Lo ocurrido a nuestro entrevistado se repite. Por lo general, coincidiendo con la presencia de un amigo, o amigo de amigo, en algún establecimiento toman conocimiento de que allí falta personal. Roco es cocinero en un bar del puerto, cuando se marcha el encargado de fregar la vajilla, le avisa a su amiga Lía que acuda a la firma, que tendrá trabajo. Lía a su vez, pasadas unas semanas, «traspasa» su empleo a Laura, cuando a ella unos conocidos le cuentan que, en un hotel de la zona de L'Arenal, necesitan alguien para la limpieza.

Así circula la información, uno se lo comunica a otro, la red se pone en funcionamiento, la vacante en el trabajo al que uno renuncia, se le ofrece a alguien, que a la vez deja el suyo y lo brinda a un tercero. Cada uno va rotando de los empleos, persiguiendo mejor sueldo, jornadas más reducidas y condiciones de trabajo, en general, más favorables.

Es necesario subrayar que, la posibilidad de realizar dichos cambios se debe a que en los rubros en donde se insertan laboralmente hay una gran demanda de trabajadores. En ese sentido su comportamiento no difiere del de sus compatriotas radicados en otros puntos de España. Para el conjunto de los argentinos los porcentajes revelan que un 36\% están ocupados en el comercio y la hostelería, el $20 \%$ en la industria, el 14\% se dedican a actividades inmobiliarias y a la intermediación financiera, el 7\% a la educación y a la sanidad (médicos, psicólogos, dentistas, profesores - especialmente particulares), un $2 \%$ se encuentra en la agricultura, el 4\% en los transportes, el $7 \%$ en la construcción y los restantes en servicios diversos ${ }^{66}$.

En el caso de Baleares la inserción laboral de los más jóvenes se inicia desempeñándose como camareros, relaciones públicas de lugares de diversión: «tarjeteros» (los que reparten, sobre todo, entre los jóvenes estudiantes que lle-

66 Actis y Esteban, 2007: 241. 
gan a Mallorca de viaje de fin de curso, tarjetas de discotecas y bares para que acudan a esos sitios), recepcionistas, mucamas en hoteles, cocineros, ayudantes de cocina, lavaplatos, mensajeros, teleoperadores, venden artesanía en las ferias y en la playa - en estos últimos años han proliferado los desfiles de «pareos», inclusive con música de fondo, a la orilla del mar, se trata de parejas donde mientras la mujer desfila su compañero va ofreciendo su mercadería-, realizan tareas de mantenimiento, pintura en los barcos, en viviendas y en hoteles. Los que tienen más edad, en especial las mujeres, pueden cuidar ancianos o niños.

En los empleos vinculados a la atención al público son muy requeridos. Se desempeñan como comerciales en panaderías, tiendas de ropa y de complementos, cibers, etc. Su presencia física que, como ellos mismos manifiestan, «nos mimetiza a los españoles», les ayuda, también el nivel educativo. En general, tal como vimos en un ejemplo de párrafos anteriores, la mayoría posee una capacitación más alta de la requerida por los trabajos que ocupan.

Un perfil del grado de instrucción de los argentinos lo ofrece el Observatorio de Inmigración de Mallorca. Según este organismo, los empadronados en el ayuntamiento de Mallorca, al $1 .^{\circ}$ de enero de 2007, tienen el siguiente nivel de estudios

Cuadro 5. Población argentina en palma según nivel de estudios. Padrón municipal AL 1-1-200767

\begin{tabular}{|l|r|}
\hline \multicolumn{1}{|c|}{ Nivel de estudios } & Totales \\
\hline Sin estudios & 1.867 \\
Primaria & 731 \\
Graduado escolar & 4.573 \\
Bachillerato & 3.139 \\
Formación profesional & 665 \\
Grado medio & 717 \\
Titulado superior & 902 \\
\hline Total & 12.594 \\
\hline
\end{tabular}

Los datos acerca de la población sin estudios se refieren a los niños que aún no han alcanzado la edad para alfabetizarse. Extrayendo del total a los menores, alrededor del $30 \%$ de los restantes ha cursado el bachillerato y el $7 \%$ estudios de grado medio, mientras que el $9 \%$ tiene superiores. La diferencia en-

67 Observatori Municipal de la Immigració (Palma de Mallorca, Maig, 2007). 
tre el número de los que han concluido el bachillerato y los que han continuado su formación es significativa. La edad de arribo de los inmigrantes a Palma podría ser uno de los elementos que expliquen el escaso porcentaje de jóvenes con una graduación superior. En definitiva, no han tenido tiempo para concluir sus estudios.

Respecto a su distribución en la isla, los municipios que les han acogido están ubicados en la costa sur, alrededor del $75 \%$ residen en esa zona, aunque fundamentalmente el de Palma es el que concentra más de la mitad de ese porcentaje, después hallamos a ayuntamientos como Calvià, Llucmajor y en menor medida Andratx. En el otro extremo, en el norte, Alcudia posee el 5\%, mientras que en los del interior su presencia se reduce.

Los marplatenses viven en ámbitos en donde previamente habían ido llegando los «pioneros». Dentro del de Palma, los argentinos son el colectivo de extranjeros más numeroso, representando el $15 \%$ del total de los empadronados ${ }^{68}$.

Las 12.594 personas que refleja el padrón del ayuntamiento de Palma en 2007 se encontraban en los siguientes sectores de la ciudad: el 8\% en la Ciudad Antigua; $6 \%$ en el Este; $18 \%$ en Estaciones; $12 \%$ en el Litoral de Levante; $11 \%$ en el Levante Norte; $6 \%$ en el Levante Sur; $13 \%$ en Mestral; $5 \%$ en Norte, y $18 \%$ en Poniente ${ }^{69}$.

Ellos están repartidos por distintos barrios, Bons Aires, Es Camp Redo, Arxiduc y Son Cotoner - todos ubicados en la zona céntrica de Estaciones-; Es Coll d'en Rabassa, Can Pastilla y el Arenal, en el Litoral del Levante y Cala Major, en el Poniente.

En la cuestión que nos concierne, los marplatenses que viven en Palma, según los testimonios que obtuvimos, fueron escogidas dos áreas, el Arenal y Cala Major, esta última, como núcleo de una zona que incluye Santa Catalina y Porta Nous. El Arenal, que pertenece en parte al municipio de Palma de Mallorca y en parte a Llucmajor, es conocido como la Playa de Palma. Se trata de una franja de casi cinco kilómetros donde están localizadas una de las mayores concentraciones hoteleras de la isla, concomitante a ello existe también una extensa oferta de restaurantes, bares, discotecas, comercios, compañías de alquiler de coches, lugares para actividades deportivas - pista de tenis, centros de buceo, etc.- Mientras que Cala Major, además de encontrarse ubicado en la zona urbana de Palma, también es un centro de ocio y turismo importante que posee disponibilidad de vivienda modesta a precios más accesibles ${ }^{70}$.

68 Observatori Municipal de la Inmigració (Palma de Mallorca, Març 2006).

69 Observatori Municipal de la Igualtat, 2007.

70 En el 2001 Cala Major tenía un 43,25 de población extranjera. «El 50\% de vecinos de Cala Major son extranjeros». El Mundo/Baleares (Baleares, 18 de febrero de 2002). 
En ninguno de los dos casos podríamos hablar de barrios étnicos. Los argentinos, específicamente lo marplatenses, residen allí junto a los españoles y a otros colectivos de inmigrantes. Sin embargo, en ambos se constituyen en la mayor población de origen extranjero extracomunitario. Específicamente en S'Arenal convivían al 1. ${ }^{\circ}$ de enero de 2006, 70 nacionalidades, los alemanes eran los más numerosos (304 personas), junto a los senegaleses (204) y argentinos $(215)^{71}$. Para estos últimos, el barrio es su territorio, lo conocen muy bien, saben en qué calles pueden buscar el alojamiento más económico, dónde encontrarán a sus conocidos de Mar del Plata, dónde están los locutorios para poder hablar con los del otro lado del Atlántico — en general éstos también funcionan como cibers-, cuáles son los comercios que tienen una oferta gastronómica o culinaria argentina. Al respecto, tanto el locutorio como los bares - estos últimos aúnan las funciones de venta de productos con la de lugar donde se puede consumir-, constituyen núcleos de encuentro, en un ámbito donde el que acude identifica a los que también lo hacen y ese contexto les permite hablar con códigos comunes. Además pueden comprar yerba mate o comerse un alfajor de dulce de leche, a la vez que se comunican a través de «videoconferencia» con su gente en Mar del Plata o compran una tarjeta telefónica. El uso de tarjetas es habitual en los inmigrantes, pero en el caso de los marplatenses, justamente porque el grupo es muy numeroso, está a la venta una especial: "Yo tengo una tarjeta para llamar a Mar del Plata que directamente marcás el código. Y en vez de marcar el 0054, directamente marcás el número como si estuvieras en Mar del Plata».

Respecto a los comercios es necesario hacer una distinción. Por una parte están aquellos con una oferta destinada a todos los públicos, como las parrillas y restaurantes, que podemos encontrar distribuidos en los lugares más turísticos de la isla ${ }^{72}$. Por otra, los que podríamos definir como étnicos, cuya clientela se circunscribe sólo a los argentinos, o a los rioplatenses (uruguayos y argentinos). Éstos están instalados en áreas donde la demanda esta garantizada, es decir que la presencia de aquéllos es abundante.

"Yo vivo en Palma hace cuatro, y esto cada vez se parece más a Mar del Plata, además de estar superpoblado de gente criolla y marplatense, está lleno

71 Senegaleses y argentinos empatados en S'Arenal. Última Hora (Baleares, 19 de febrero de 2006).

72 En las Páginas Amarrillas, guía de comercios en España, se anuncian 14 restaurantes en Baleares, de los cuales nueve están en Mallorca. En el Portal Argentinos en Palma existen 14, incluyendo algunos que sólo son bares. http://www.argentinosenpalma.com/restaurantesargentinos.htm 
de panaderías, pizzerías, carnicerías y parrillas argentinas», manifestaba Pablo en un blog del periódico Clarín ${ }^{73}$.

Mientras que otro narraba: «Acá hay muchos lugares que venden productos argentinos, y hasta las carnicerías españolas vieron el negocio vendiendo cortes argentinos. Es imposible tener antojo de algo, lo conseguís, aunque bastante más caro. Sabes dónde ir por el boca a boca. Todos conocemos La Romanita, una de las primeras en vender pastas caseras, Tostus, panadería (¡hasta con postre Balcarce! ${ }^{74}$ ) también $\mathrm{MDQ}^{75}$, otra panadería. Hay muchas parrillas, roticerías, pizzerías y bares argentinos $\rangle^{76}$.

Beatriz, que reside en El Arenal, nos contaba que se trasladaba a Palma los domingos, pero que dejó de hacerlo a partir de tener uno de esos comercios en el barrio: "Yo antes me iba los fines de semana al "Tostus", a la mañana a comprarme el tostadito, tomarme el café con leche, a comprar las facturas, comprar la yerba, comprar los ravioles para el domingo. Pero ahora lo tengo a tres cuadras de mi casa, porque pusieron una sucursal por la demanda que hay acá, en el Arenal» ${ }^{77}$.

Según Leo: «Tenemos Panadería argentina, pizzería argentina, telefónica argentina (risas), eh... heladería argentina donde vamos a tomarnos el cucurucho de dulce de leche, eh... estamos cada vez más cómodos, ¿o no? ${ }^{78}$ 》.

El barrio además incluye la playa, ésta no sólo incide sobre el tipo mercado laboral que va estructurándose en su entorno, sino que se constituye en el espacio público de reunión por excelencia, generando la posibilidad de realizar una serie de actividades en las que reproducen sus prácticas culturales. Los marplatenses juegan al fútbol o al voleybol, toman mate e inclusive realizan sus asados en la playa. En verano, se juntan y encienden fuego y colocan las parrillas en la arena, al lado del mar. De esta manera se impregna el ambiente del olor característico de cualquier ciudad argentina un domingo al mediodía, huele a carne asada. En invierno buscan en la montaña los lugares permitidos para hacer fogatas.

73 Extraído del blog: http://weblogs.clarin.com/nideacanidealla/archives/2007/11/tradicion_argentina_en_palma_de_mallorca.html

$\overline{74}$ Postre que, junto a los alfajores, es característico de Mar del Plata.

75 MDQ es el código del aeropuerto de Mar del Plata.

76 Extraído del blog: http://weblogs.clarin.com/nideacanidealla/archives/2007/11/recomendados_una_verdad_sobre_italia_y_servicios_desde_mallorca.html

77 Entrevista realizada a Beatriz, 29 años, casada, llegó a Mallorca en 2002, estudios universitarios incompletos, nacionalidad sueca.

78 Entrevista realizada a Leo, 30 años, casado, llegó a Mallorca en 2001, estudios universitarios incompletos, nacionalidad italiana. 
En este caso se diferencian del resto de los inmigrantes, no existe por su parte apropiación y monopolio de espacios públicos del tipo de parques y plazas, se trata de ámbitos abiertos que comparten con el resto de la población.

Alicia, una de nuestras entrevistadas, nos decía que caminar por la playa era igual que hacerlo en Mar del Plata, se encontraba con amigos o conocidos cada dos pasos. Igual situación se repite paseando por algunas zonas de Palma: «Marplatenses somos muchos, eh, la verdad que salir una noche por el paseo Marítimo, salís y es como salir en Alem o Constitución ${ }^{79}$ en Mar del Plata».

Por otra parte, además de reunirse con marplatenses, mantienen contactos cotidianos con sus amigos y familiares que quedaron en Argentina. Todos nos han manifestado que utilizan internet a diario, además leen la prensa marplatense, La Capital, para estar al día de las noticias de su ciudad. Alguno inclusive participa del foro «marplatenses en el mundo», que mantiene dicho periódico.

A modo de conclusión, hemos intentado describir el modelo migratorio de un grupo de argentinos, en general perteneciente a las camadas más jóvenes, oriundos de una ciudad turística del litoral atlántico que se trasladan a Mallorca, alguno de ellos inclusive lo hace para trabajar la temporada de verano y luego regresan. Las posibilidades de insertarse en un mercado laboral muy semejante, en el que abundan los empleos estacionales, relacionados con el sector turístico, han posibilitado este tipo de migración. Una red social se fue generando a partir de los núcleos de argentinos instalados en Mallorca a raíz del exilio de los años 70, de la hiperinflación de los 90 y de las informaciones que fueron brindando los que regresaban, cada año, a Mar del Plata. Esa red desempeña un papel fundamental, ella agiliza la elección del destino, dinamizando los flujos hacia la isla, además de reducir los costos inmigratorios, facilita la instalación y posterior asentamiento de dichos migrantes.

Finalmente, la pregunta que nos surge se refiere a sus proyectos de asentamiento definitivo, temática en la que no se ha hecho ningún hincapié. Se trata de una cuestión muy compleja y en este caso entiendo que, dado el poco tiempo que ha transcurrido desde que se produce el comienzo del último flujo (2001), es muy difícil realizar un diagnóstico acerca de cuáles serán las intenciones de sus protagonistas. Sólo podríamos aventurar que los más jóvenes - su juventud es una de las características del colectivo que analizamos- parecería que transmiten la imagen de que su estancia es coyuntural, momentá-

79 Se trata de dos arterias de la ciudad de Mar del Plata en las que se concentran bares y pubs, especialmente frecuentados por jóvenes.

Entrevista realizada a Daniela, 28 años, casada, llegó a Mallorca en 2000, estudios secundarios, permiso de residencia y de trabajo. 
nea. Inclusive, nos aventuramos a decir que sus expectativas responden a esa idea de que todo se realiza en el corto plazo, no hay una planificación sobre el futuro. Sin embargo, no sabemos hasta qué punto la crisis económica actual va a influir adelantando el regreso.

\section{BIBLIOGRAFÍA}

Actis, Walter y Esteban, Fernando, «Argentinos hacia España (sudacas en tierras "gallegas"): el estado de la cuestión», Susana NOVICK (comp.), SUR-NORTE Estudios sobre la emigración reciente de argentinos, Buenos Aires, editorial Catálogos, 2008: 205-258.

Arango, Joaquín, «Enfoques conceptuales y teóricos para explicar la migración», Revista Internacional de Ciencias Sociales, 165 (UNESCO, 2000): 33-47.

Arango, Joaquín, «La fisonomía de la inmigración en España», P. Reques (ed.), El nuevo orden demográfico, Madrid, Banco Bilbao Vizcaya Argentaria, 2002: 237-262.

Aruj, Roberto, Por qué se van. Exclusión, frustración y migraciones, Buenos Aires, Editorial Prometeo, 2004.

Basualdo, Eduardo, Estudios de Historia Económica Argentina, Buenos Aires, Siglo XXI, 2006.

Berenblum, Rubén, «Introducción», Elda González Martínez y M.a Asunción Merino Hernando, Historias de Acá. Trayectoria Migratoria de los argentinos en España, Madrid, CSIC, 2007: 19-38.

Conselleria d'Economia, Hisenda i Innovació, Baleares, un mundo de oportunidades, Palma de Mallorca, Govern Balear, s/d.

Direcció General D'immigració, Estratègies i actuacions en immigració. Balears, Govern de les Illes Balears, Conselleria d'Afers Socials, Promoció i Immigració, 2008.

Gallo, Marcos Esteban, «Precariedad laboral en el mercado de trabajo marplatense», Revista Faces (Facultad de Ciencias Económicas y Sociales), 16/enero-abril (Mar del Plata, 2003): 109-131.

García, Paola, Le rôle des organisations civiles et des institutions religieuses dans les processu d'intégration des immigrés. Argentins et Equatoriens en Espagne (1998-2006). Tesis doctoral inédita, Université Paris VIII, 2006.

Goldberg, Alejandro, «Tú, sudaca». Las dimensiones histórico-geográficas, sociopolíticas y culturales alrededor del significado de ser inmigrante (y argentino) en España, Buenos Aires, Prometeo libros, 2007. 
González Martínez, Elda, «Españoles en América e iberoamericanos en España: cara y cruz de un fenómeno», Revista Arbor, n. ${ }^{\circ}$ 607/CLIV (Madrid, julio 1996): 15-35.

González Martínez, Elda, «L'esperienza della diversità. Gli argentini in Spagna», Revista Studi Emigrazione, Revista trimestrale dell Centro Studi Emigrazione, 170/XLV (Roma, aprile-giugno 2008): 319-340.

González Martínez, Elda y Merino Hernando, Asunción, Historias de acá. La trayectoria migratoria de los argentinos en España. Madrid, CSIC, 2007.

Grupo de Estudios del Trabajo, Informe socio-laboral de la municipalidad de General Pueyrredón. Mar del Plata, Universidad de Mar del Plata, 2008.

Institut Balear d'Estadística, Revisió Padró 1 de enero de 2007, Palma de Mallorca, Direcció General d'Economia, Govern Balear, 2008. http://www.caib.es/ibae/demo/estrangers/III1.htm.

Instituto Nacional de Estadística, Avance del Padrón Municipal 2007. Población extranjera por nacionalidad y país de nacimiento, Madrid, Instituto Nacional de Estadística, 2007. http://www.ine.es/inebmenu/mnu_cifraspob.htm\#1

Instituto Nacional de Estadísticas y Censos (INDEC), Censo Nacional de 2001. http://www.indec.mecon.ar/

Jofre, Ana, Emigración de argentinos a Mallorca, 1990-2002, Fundació Cátedra Iberoamericana de la Universitat des les Illes Balears, 2003, http:/www.uib.es/catedra_iberoamericana/pdf/investig_jofre.pdf

Lindenboim, Javier, El reparto de la torta, Buenos Aires, CI, 2005.

Massey, Douglas, «Why does the Immigration Occur? A theoretical Synthesis», Hirschman, Charles, Kasinitz, Philip y De Wind, Josh (eds.), The Handbook of International Migration: The American Experience, Nueva York, Russel Sage Foundation, 1999: 34-52.

Mazorra, Ximena, Iván Heyn, Lucila Baldi y Alejandra Beccaria, «Área Económica Local de Mar del Plata. Estructura productiva y mercado de trabajo», http://www.aset.org.ar/congresos/7/09002.pdf

Merino Hernando Asunción y González Martínez, Elda, Las migraciones Internacionales, Madrid, Dastin Ed., 2006.

Novick, Susana. Evolución reciente de la política migratoria argentina. Buenos Aires, Instituto de Investigaciones Gino Germani, s/d.

Observatori Municipal de la Igualtat, Estadisticas de Población, tablas, datos al 1. ${ }^{\circ} \mathrm{de}$ enero de 2007. http://www.observatoripalma.org/acercade/estadisticas/index.es. html?tIte $=$ datos-a-1-1-2007\&sqlw_tema=75

Observatori Municipal de la Inmigració, Quaderns de l' Observatori, Març 2006. http://www.observatoripalma.org/imgdb/archivo_doc5439.pdf 
Observatori Municipal de la Inmigració, Quaderns de l' Observatori. Maig 2007. http://www.observatoripalma.org/imgdb/archivo_doc5439.pdf

Pajares, Miguel, Inmigración y mercado de trabajo. Informe 2008, Madrid, Ministerio de Trabajo e Inmigración, 2008.

Palomino, Héctor, Pobreza y desempleo en la Argentina. Problemática de una nueva configuración social, Buenos Aires, Cespa, FCE-UBA, 2003.

Parrado, Emilio, «La etnoencuesta como alternativa metodológica para el estudio de las migraciones internacionales en América Latina», Adela Pellegrino (comp.), Migración e integración. Nuevas formas de movilidad de la población, Montevideo, Ediciones Trilce, 1992: 78-86.

Rodríguez López, Miguel, «Causas económicas de la migración de los marplatenses a a la isla de Mallorca (España) entre los años 1998-2001 (Una aproximación cualitativa)». Revista Faces (Facultad de Ciencias Económicas y Sociales), 16/enero-abril (Mar del Plata, 2003): 7-25.

Sevares, Julio. Por qué cayó la Argentina, Buenos Aires, Norma, 2002.

Torres, Juan C. y Pastoriza, Elisa, «Mar del Plata, un sueño de los argentinos», M. Madero y F. Devoto (ed.), Historia de la vida privada en la Argentina, Buenos Aires, Taurus, 1999: 49-77.

\section{SOCIAL NETWORKS AND EMIGRATION: THE CASE OF THE POPULATION OF MAR DEL PLATA}

This paper describes the last surge of Argentinian migration to Spain, which took place as a result of the crisis which affected Argentina at the beginning of the new millennium. From interviews, press documentation and statistical sources, we analyse the role of social networks as a factor which enables, in the first place, the choice of destination for emigrants from Mar del Plata whereas it contributes later to the settlement process in the Balearic Islands.

Key words: Emigration, social network, Mar del Plata population, Spain. 